\section{Atomic Energy and Agriculture}

Edited by C. L. Comar. (A Symposium presented on December 27-29, 1955, at the Atlanta Meeting of the American Association for the Advancement of Science and Co-sponsored by the Oak Ridge Institute of Studies, under contract with the United States Atomic Energy Commission.) (Publication No. 49.) Pp. $x+450$. (Washington, D.C. : American Association for the Advancement of Science; London: Bailey Bros. and Swinfen, Ltd., 1957.) $86 s$.

F twenty-two specialist contributions to this book, eight deal with various aspects of the use of ionizing radiations for such purposes as pest destruction, sterilization and plant breeding. These are of great interest and carefully assess the advantages and disadvantages of the techniques. The remaining fourteen papers are on assorted biochemical topics in which radioactive tracers have been used as a research tool. It is remarkable that after more than a decade of the use of isotopes in biochemical research, it is still thought worth while to combine in a single volume a number of topies which have in common only the use of this single research method.

The papers themselves are nevertheless of value, written as they are by experts in the various fields. As one would expect, all the contributors are American, but most of them have international reputations. Thus, to name but a few, we find C. $L$. Comar, who has not only edited the volume but also, with R. H. Wasserman, has contributed a paper on macronutrient metabolism. Lactation and hormones are dealt with by J. C. Shaw and S. Lakshmenan, and photosynthesis by N. E. Tolbert. If anything, the emphasis of the symposium as a whole is in favour of work on plants and soil rather than on animals, but most agricultural topics of importance are covered. Papers cited in the references are listed by author and date, and in about half of them the title is included. The book is well produced and printed and will be found useful by most biological research workers.

R. F. GLASCOCK

Annals of the International Geophysical Year Vol. 4, Parts 1, 2, and 3. Pp. 202. Vol. 4, Parts 4, 5, 6 , and 7. Pp. 203-393. Vol. 5, Parts 1, 2, and 3. Pp. 244. Subscription per volume : 120s. ; 17 dollars. (London and New York: Pergamon Press, 1957.)

VOLUME 4 of the Annals of the International Geophysical Year contains instructions by leading authorities for the observations of radioactivity in the atmosphere and oceans, aurora, airglow, noctilucent clouds, latitude and longitude, geomagnetism, seismology and cosmic rays to be made during the International Geophysical Year. It includes descriptions of instruments, practical hints on observing, methods of reducing the observations, and notes on the specific problems on which it is hoped these observations will throw light. The articles on aurora and airglow go rather beyond this and are interesting short text-books in themselves.

Volume 5 contains instructions for the observations of the distribution of ozone in the atmosphere for auroral photography with the special all-sky camera developed by W. Stoffregen at Upsala Ionospheric Observatory, and the Manual of Communication for radio transmissions in the Antarctic during the Geophysical Year. Part I on ozone gives full instruc. tions for the use of the Dobson ozone spectrophoto- meter and the calculation from its readings of the vertical distribution of ozone. The volumes should be useful as descriptions of techniques long after the International Geophysical Year has come to an end. The production by the Pergamon Press, especially the reproductions of the autographic records, complicated circuit diagrams, and instrument drawings, is excellent.

G. A. BULL

\section{The Exact Sciences in Antiquity}

By O. Neugebauer. Second edition. Pp. xvi $+240+$ 14 plates. (Providence, R.I. : Brown University Press, 1957.) 6 dollars.

DUING the six years that have elapsed since this standard work first appeared, numerous further contributions have been made (not least by its distinguished author) to our understanding of ancient Eastern mathematics and astronomy and of their relationship to Hellenistic science. The preparstion of this second edition has afforded Dr. Neugebauer an opportunity for adjusting the text and revising the closely printed pages of notes and references in the light of the most recent revelations. Of particular interest is the novel explanation of how the Egyptians' choice of thirty-six 'decanal' constella. tions (arising from the decimal structure of their civil calendar) led on directly to the familiar division of the night, and eventually of the day, into twelve hours each. However, the principal additions to the book are two long appendixes; the first deals with the geometrical techniques of the Ptolemaic planetary theory and with the modifications introduced by Copernicus; the second illustrates how some of the developments of Greek mathematics originated from the practical needs of astronomy and geodesy. This book (accurately reprinted in Denmark) has become an indispensable tool for students of the obscure origins of our mathematical heritage ; they will be gratified to find it re-sharpened for their use.

\section{A. Armitage}

\section{Inorganic Chemistry}

A Textbook for Advanced Students. By Dr. E. de Barry Barnett and Dr. C. L. Wilson. Second edition. Pp. xvi +588. (London and New York : Longmans, Green and Co., Ltd., 1957.) 35s. net.

TN the preparation of a new edition of this useful book many of the sections have been rewritten and brought up to date, and the size has been somewhat increased. Since some references to literature are given, the information in the original sources can be turned up if required. The book is intended for advanced students, so that many parts of the subject dealt with in elementary works are omitted. This makes it less suitable as a book of reference. The trestment is sound and accurate and the book is interesting to read. Occasionally, the authors refer in rather severe terms to current opinions and sometimes advance theories of their own. In one case at least, namely, on the action of nitric acid on metals, their theory is certainly incorrect; as a general rule it is better not to introduce such matter into $a$ book intended for students. The book will be found very useful in preparation for university degrees or comparable qualifications and will certainly be helpful to teachers of advanced pupils in schools. It is very well printed on a large page. Although the authors have added a couple of pages of 'stop-press' information, the text is already out of date in a few cases, for example, on the hydrides of boron.

J. R. Partinaton 